\title{
Orthogonal Bodipy Trimers as Photosensitizers for Photodynamic Action
}

\author{
Tugba Ozdemir, ${ }^{\dagger}$ Jose Luis Bila, ${ }^{\ddagger}$ Fazli Sozmen, ${ }^{\S}$ Leyla T. Yildirim, ${ }^{\|}$and Engin U. Akkaya*,†, \\ ${ }^{\dagger}$ UNAM-National Nanotechnology Research Center and ${ }^{\ddagger}$ Department of Chemistry, Bilkent University, 06800 Ankara, Turkey \\ ${ }^{\S}$ Department of Nanotechnology Engineering, Cumhuriyet University, 58140 Sivas, Turkey \\ "Department of Engineering Physics, Hacettepe University, Beytepe, 06800 Ankara, Turkey
}

\section{Supporting Information}

ABSTRACT: Orthogonally linked BODIPY units show exceptional intersystem crossing efficiencies. We now report orthogonal BODIPY trimers with strong absorption in the visible region and high singlet oxygen generation capability. The X-ray diffraction structure confirms that the two peripheral BODIPY units are at a perpendicular angle to the core structure.

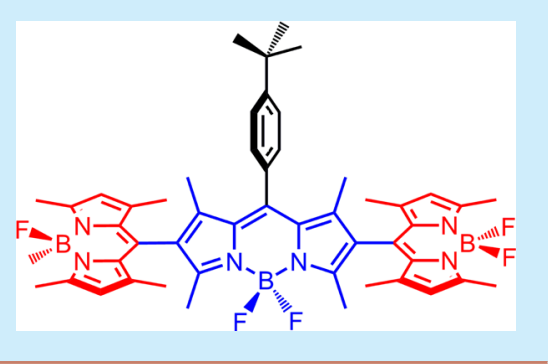

$\mathrm{B}$ ODIPY dyes have grown to become a family of compounds with diverse applications rivaling that of porphyrins. ${ }^{1}$ From chemosensors to logic gates, ${ }^{2}$ photodynamic therapy (PDT) agents ${ }^{3}$ to dye-sensitized solar cell (DSSC) photosensitizers, ${ }^{4}$ simple derivatives of BODIPY have proven to be quite valuable. In addition, with slight core modifications, such as expanded rings ${ }^{5}$ or pyridine substitutions, ${ }^{6}$ chemical diversity can be further enhanced. A broad palette of colors $\left(\mathrm{S}_{0}-\mathrm{S}_{1}\right.$ transition $)$ can be obtained through straightforward derivatizations. ${ }^{7}$

As a part of our ongoing efforts toward improved photosensitizers for photodynamic therapy, ${ }^{8}$ we recently reported $^{9}$ that orthogonal Bodipy dimers have unique "degenerate" excited-state characteristics which make them exceptionally effective in photosensitized generation of singlet oxygen. This leads to a significant step in the right direction because incorporation of heavy atoms to facilitate intersystem crossing (isc) often results in increased dark toxicity ${ }^{10}$ (i.e., toxicity of the photosensitizer compound itself, in the absence of light). Thus, the orthogonal dimer approach appears to be a straightforward methodology for the transformation of an ordinary dye into an effective photosensitizer, without heavy atom incorporation.

It is important to probe the limitations ${ }^{11}$ of this approach both theoretically and experimentally. We were pleased to report $^{12}$ that simple derivatives of the orthogonal dimers covalently attached to upconverting nanoparticles (ucnp) can be excited at $980 \mathrm{~nm}$ to generate singlet oxygen, which makes the orthogonal Bodipy dimer-ucnp conjugates viable candidates as potential sensitizing agents for PDT.

It would be equally important to investigate an orthogonal Bodipy trimer as a model for extended orthogonality. To that end, we targeted compounds $\mathbf{5 a}$ and $\mathbf{5} \mathbf{b}$ for synthesis. The synthesis work (Figure 1) for 5a started with a commercially available aldehyde, p-tert-butylbenzaldehyde. tert-Butyl sub-

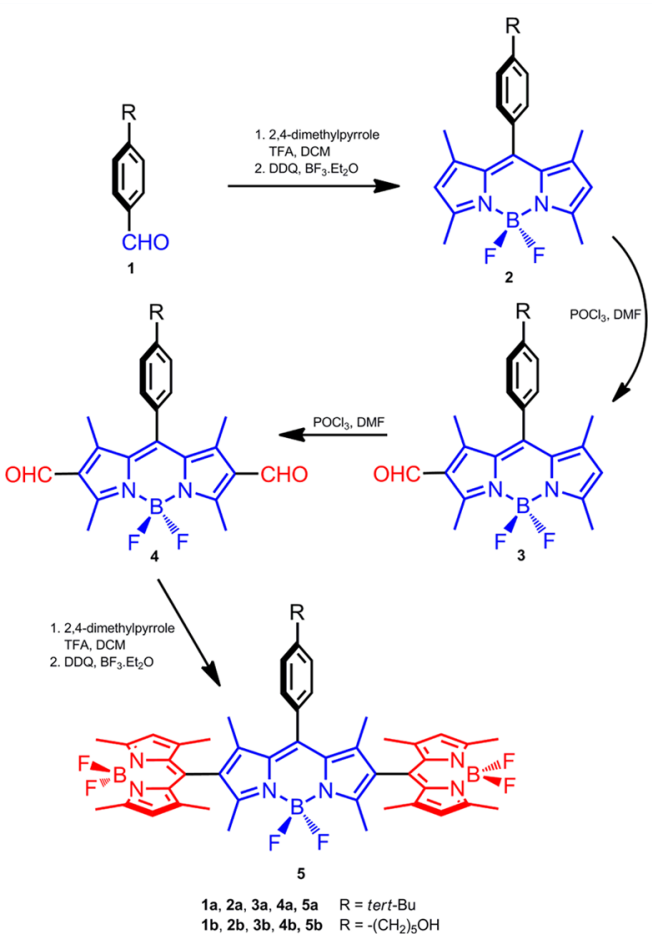

Figure 1. Synthesis of the orthogonal Bodipy trimers $\mathbf{5 a}$ and $\mathbf{5 b}$.

stituents may contribute to organic solubility and also facilitate formation of crystals suitable for X-ray analysis. Construction of the Bodipy core in accordance with the well-established procedures $^{13}$ results in compound 2a. Two consecutive Villsmeyer-Haack-type formylations ${ }^{14}$ give 2,6-diformyl de-

Received: August 12, 2016

Published: September 15, 2016 
rivative 4a. This compound was then converted to the target trimer (5a) by applying the usual BODIPY synthesis protocol. Compound $\mathbf{5 b}$ was synthesized similarly, with only difference being the use of 4-(5-hydroxypentyl)benzaldehyde (1b) instead of $\mathbf{1} \mathbf{a}$. The trimer $\mathbf{5 b}$ was targeted for an additional potential for further functionalization. Both target compounds were characterized analytically $\left({ }^{1} \mathrm{H},{ }^{13} \mathrm{C}\right.$, and HRMS, see the Supporting Information). The absorption spectrum of 5a in dichloromethane (DCM) shows a major band in the visible region with a peak at $507 \mathrm{~nm}$ and a shoulder at $522 \mathrm{~nm}$. The extinction coefficient at $507 \mathrm{~nm}$ is $181500 \mathrm{~cm}^{-1} \mathrm{M}^{-1}$. Crystals of 5a suitable for single-crystal X-ray diffraction study were obtained by slow evaporation of the DCM solution. The X-ray structure of the compound 5a reveals three orthogonal planes defined by the meso-tert-butylphenyl substituent, the core BODIPY plane, and the planes defined by the peripheral BODIPY units. The angles between these planes are essentially perpendicular to each other as expected (Figure 2). Our

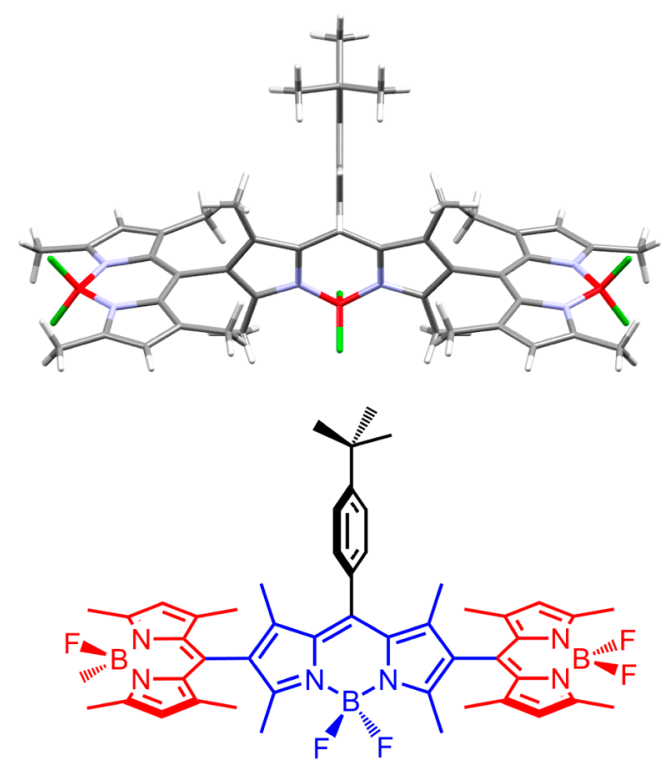

Figure 2. (Top) X-ray diffraction structure of the BODIPY-trimer 5a. (Bottom) Planes defined by the peripheral BODIPY units (red) are at an $81-82^{\circ}$ angle to the core unit (blue structure), whereas the mesophenyl substituent is at a $90^{\circ}$ angle to the same core BODIPY plane.

previous computational work suggests that although the peripheral BODIPY units are placed at about an $80^{\circ}$ angle (i.e., less than $90^{\circ}$ ) in relation to the BODIPY core it is enough to cause degeneracy in the excited state.

A solution of compound 5a in DCM solution sensitized dissolved oxygen, and the characteristic phosphorescence emission of singlet oxygen at $1270 \mathrm{~nm}$ was detected (SI). By using 1,3-diphenylisobenzofuran as a singlet oxygen trap, relative singlet oxygen generation capacities were determined. 1,3-Diphenylisobenzofuran is a selective trap for singlet oxygen. The reaction proceeds with an initial $[4+2]$ cycloaddition of the singlet oxygen, as isobenzofurans are one of the most reactive dienes in such cycloaddition reactions due to aromatization in the cycloadduct (Figure 3). The intermediate species is unstable, and it decomposes into 1,2-dibenzoylbenzene. The net result is a decrease in the absorption of isobenzofuran (Figure 4); thus, the progress of the reaction can be followed at $410 \mathrm{~nm}$ (Figure 5).
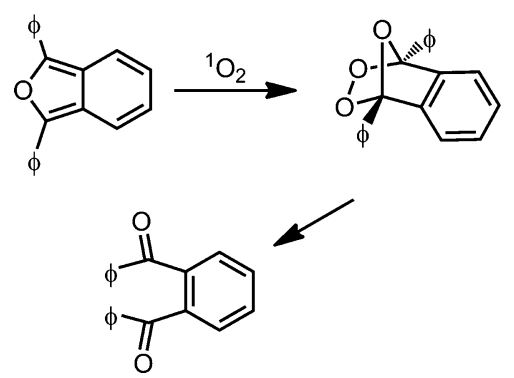

Figure 3. Reaction of 1,3-diphenylisobenzofuran (DPBF) with singlet oxygen leading to the decrease in the absorbance at $414 \mathrm{~nm}$.

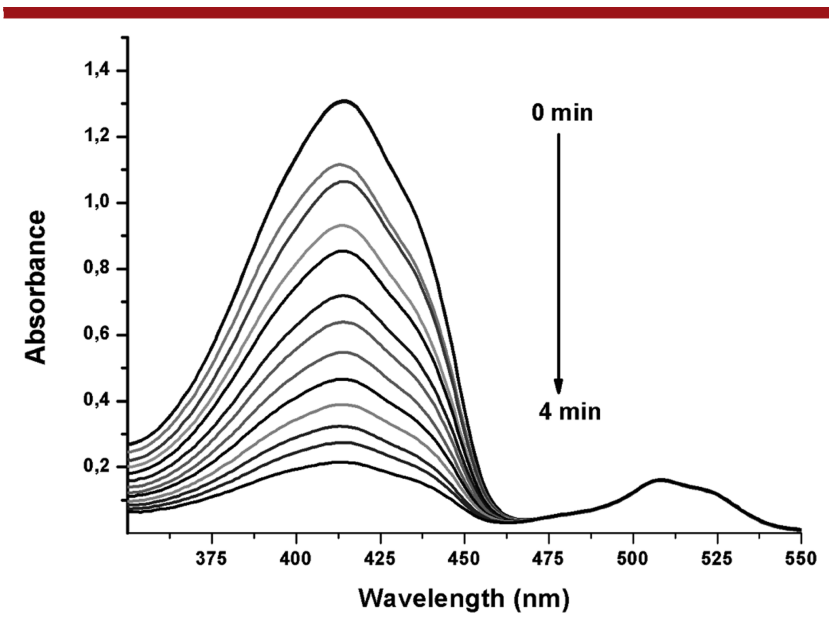

Figure 4. Decrease in the absorbance of the singlet oxygen trap DPBF in DCM solution at the peak absorbance of the trap compound in the presence of $\mathbf{5 a}$. When kept in the dark absorbance does not change; however, once irradiation begins, in $4 \mathrm{~min}, 90 \%$ of the DPBF disappears. Concentration of the trimer $5 \mathrm{a}$ was $0.77 \mu \mathrm{M}$, and the DPBF concentration is $56.6 \mu \mathrm{M}$. The irradiation was carried out using a green LED array with a fluence rate of $2.5 \mathrm{~mW} / \mathrm{cm}^{2}$.

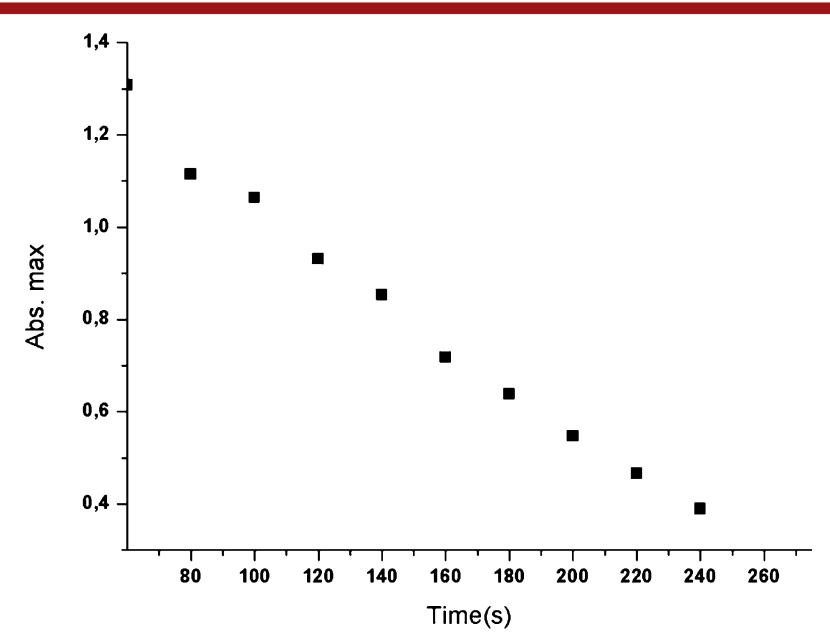

Figure 5. Plot of absorbance as a function of time at the maximum of the DPBF peak at $414 \mathrm{~nm}$ in the presence of $0.77 \mu \mathrm{M}$ trimer $5 \mathrm{a}$. The experiment was carried out under green LED excitation with a fluence rate of $2.5 \mathrm{~mW} / \mathrm{cm}^{2}$. The initial concentration of the DPBF concentration was set at $56.6 \mu \mathrm{M}$.

Singlet oxygen quantum yields of both compounds in DCM were determined as 0.53 for $\mathbf{5 a}$ and 0.55 for $\mathbf{5 b}$. Thus, we were able to show that orthogonality of the chromophores in the compounds $\mathbf{5 a}$ and $\mathbf{5 b}$ resulted in degenerate excited states 
with facilitated intersystem crossing to yield efficient singlet oxygen generators. Functionalization in $\mathbf{5 b}$ also reveals that it should be possible to use the trimer compound as a photosensitizer module and attach it to molecular entities or to nanoparticles as needed. Since it is important to have a general approach for the design of efficient photosensitizers without the incorporation of heavy atoms, the orthogonally chromophores are likely to be at the center of attention.

In addition to the photosensitizing properties of the target compounds, it is also clear that the orthogonal BODIPY trimers can be utilized as chromogenic structural units. As the 2,6positions of the peripheral BODIPY units are open to substitution, it is very likely that well-defined organic frameworks can be obtained by various coupling reactions. Further work along these lines is in progress and will be reported in due course.

\section{ASSOCIATED CONTENT}

\section{S Supporting Information}

The Supporting Information is available free of charge on the ACS Publications website at DOI: 10.1021/acs.orglett.6b02418.

Synthesis procedures; additional spectral and characterization data, including ${ }^{1} \mathrm{H}$ and ${ }^{13} \mathrm{C}$ NMR and HRMS data (PDF)

X-ray data for for 5a (CIF)

\section{AUTHOR INFORMATION}

Corresponding Author

*E-mail: eua@fen.bilkent.edu.tr.

\section{Present Address}

${ }^{\perp}$ (J.L.B.) EPFL SB ISIC LCS BCH 3409 (Batochime UNIL), Av. F.-A. Forel 2, CH-1015 Lausanne, Switzerland.

Notes

The authors declare no competing financial interest.

\section{ACKNOWLEDGMENTS}

Financial support by Bilkent University in the form of a graduate student scholarship to J.L.B. is gratefully acknowledged.

\section{REFERENCES}

(1) (a) Rurack, K.; Kollmannsberger, M.; Daub, J. Angew. Chem., Int. Ed. 2001, 40, 385-387. (b) Ziessel, R.; Ulrich, G.; Harriman, A. New J. Chem. 2007, 31, 496-501. (c) Atilgan, S.; Kutuk, I.; Ozdemir, T. Tetrahedron Lett. 2010, 51, 892-894. (d) Bozdemir, O. A.; Cakmak, Y.; Sozmen, F.; Ozdemir, T.; Siemiarczuk, A.; Akkaya, E. U. Chem. Eur. J. 2010, 16, 6346-6351. (e) Ozdemir, T.; Sozmen, F. RSC Adv. 2016, 6, 10601-10605. (f) Ozdemir, T.; Sozmen, F.; Mamur, S.; Tekinay, T.; Akkaya, E. U. Chem. Commun. 2014, 50, 5455-5457. (g) Zeng, L.; Miller, E. W.; Pralle, A.; Isacoff, E. Y.; Chang, C. J. J. Am. Chem. Soc. 2006, 128, 10-11.

(2) (a) Sunahara, H.; Urano, Y.; Kojima, H.; Nagano, T. J. Am. Chem. Soc. 2007, 129, 5597-5604. (b) Yin, S. C.; Leen, V.; Van Snick, S.; Boens, N.; Dehaen, W. Chem. Commun. 2010, 46, 6329-6331. (c) Rurack, K.; Kollmannsberger, M.; Resch-Genger, U.; Daub, J. J. Am. Chem. Soc. 2000, 122, 968-969. (d) Isik, M.; Ozdemir, T.; Turan, I.S.; Kolemen, S.; Akkaya, E. U. Org. Lett. 2013, 15, 216-219. (e) Niu, L.-Y.; Guan, Y.-S.; Chen, Y.-Z.; Wu, L.-Z.; Tung, C.-H.; Yang, Q.-Z. J. Am. Chem. Soc. 2012, 134, 18928-18931. (f) Gabe, Y.; Urano, Y.; Kikuchi, H.; Kojima, H.; Nagano, T. J. Am. Chem. Soc. 2004, 126, 3357-3367. (g) Guliyev, R.; Ozturk, S.; Kostereli, Z.; Akkaya, E. U.
Angew. Chem., Int. Ed. 2011, 50, 9826-9831. (h) Erbas-Cakmak, S.; Bozdemir, O. A.; Cakmak, Y.; Akkaya, E. U. Chem. Sci. 2013, 4, 858862.

(3) (a) Kamkaew, A.; Lim, S. H.; Lee, H. B.; Kiew, L. V.; Chung, L. Y.; Burgess, K. Chem. Soc. Rev. 2013, 42, 77-88. (b) Yogo, T.; Urano, Y.; Ishitsuka, F.; Nagano, T. J. Am. Chem. Soc. 2005, 127, $12162-$ 12163. (c) Gallagher, W. M.; Allen, L. T.; O’Shea, C.; Kenna, T.; Hall, M.; Gorman, A.; Killoran, J.; O'Shea, D. F. Br. J. Cancer 2005, 92, 1702-1710. (d) Young, S. W.; Woodburn, K. W.; Wright, M.; Mody, T. D.; Fan, Q.; Sessler, J. L.; Dow, W. C.; Miller, R. A. Photochem. Photobiol. 1996, 63, 892-897. (e) Tan, X.; Luo, S.; Wang, D.; Su, Y.; Cheng, T.; Shi, C. Biomaterials 2012, 33, 2230-2239. (f) Yang, Y.; Guo, Q.; Chen, H.; Zhou, Z.; Guo, Z.; Shen, Z. Chem. Commun. 2013, 49, 3940-3942.

(4) (a) Kumaresan, D.; Thummel, R. P.; Bura, T.; Ulrich, G.; Ziessel, R. Chem. - Eur. J. 2009, 15, 6335-6339. (b) Lee, C. Y.; Hupp, J. T. Langmuir 2010, 26, 3760-3765. (c) Kolemen, S.; Bozdemir, O. A.; Cakmak, Y.; Barin, G.; Erten-Ela, S.; Marszalek, M.; Yum, J. H.; Zakeeruddin, S. M.; Nazeeruddin, M. K.; Graetzel, M.; Akkaya, E. U. Chem. Sci. 2011, 2, 949-954. (d) Rousseau, T.; Cravino, A.; Bura, T.; Ulrich, G.; Ziessel, R.; Roncali, J. Chem. Commun. 2009, 1673-1675. (e) He, J.; Benko, G.; Korodi, F.; Polivka, T.; Lomoth, R.; Akermark, B.; Sun, L.; Hagfeldt, A.; Sundstrom, V. J. Am. Chem. Soc. 2002, 124, 4922-4932. (f) Hattori, S.; Ohkubo, K.; Urano, Y.; Sunahara, H.; Nagano, T.; Wada, Y.; Tkachenko, N. V.; Lemmetyinen, H.; Fukuzumi, S. J. Phys. Chem. B 2005, 109, 15368-15375. (g) ErtenEla, S.; Yilmaz, D.; Icli, B.; Dede, Y.; Icli, S.; Akkaya, E. U. Org. Lett. 2008, 10, 3299-3302.

(5) (a) Guliyev, R.; Ozturk, S.; Sahin, E.; Akkaya, E. U. Org. Lett. 2012, 14, 1528-1531. (b) Majumdar, P.; Mack, J.; Nyokong, T. RSC Adv. 2015, 5, 78253-7825.

(6) (a) Loudet, A.; Burgess, K. Chem. Rev. 2007, 107, 4891-4932. (b) Xu, J.; Li, Q.; Yue, Y.; Guo, Y.; Shao, S. Biosens. Bioelectron. 2014, 56, 58-63. (c) Wagner, S.; Brödner, K.; Coombs, B. A.; Bunz, U. H. F. Eur. J. Org. Chem. 2012, 2012, 2237-2242.

(7) (a) Loudet, A.; Burgess, K. Chem. Rev. 2007, 107, 4891-4932. (b) Ulrich, G.; Ziessel, R; Harriman, A. Angew. Chem., Int. Ed. 2008, 47, 1184-1201. (c) Buyukcakir, O.; Bozdemir, O. A.; Kolemen, S.; Erbas, S.; Akkaya, E. U. Org. Lett. 2009, 11, 4644-4647. (d) Zhu, S.; Zhang, J.; Vegesna, G.; Tiwari, A.; Luo, F.-T.; Zeller, M.; Luck, R.; Li, H.; Green, S.; Liu, H. RSC Adv. 2012, 2, 404-407. (e) Bura, T.; Retailleau, P.; Ulrich, G.; Ziessel, R. J. Org. Chem. 2011, 76, 11091117.

(8) (a) Erbas, S.; Gorgulu, A.; Kocakusakogullari, M.; Akkaya, E. U. Chem. Commun. 2009, 4956-4958. (b) Atilgan, S.; Ekmekci, Z.; Dogan, A. L.; Guc, D.; Akkaya, E. U. Chem. Commun. 2006, 43984400. (c) Erbas, S.; Gorgulu, A.; Kocakusakogullari, M.; Akkaya, E. U. Chem. Commun. 2009, 4956-4958. (d) Ozlem, S.; Akkaya, E. U. J. Am. Chem. Soc. 2009, 131, 48-49. (e) Turan, I. S.; Yildiz, D.; Turksoy, A.; Gunaydin, G.; Akkaya, E. U. Angew. Chem., Int. Ed. 2016, 55, 28752878. (f) Kolemen, S.; Ozdemir, T.; Lee, D.; Kim, G. M.; Karatas, T.; Yoon, J.; Akkaya, E. U. Angew. Chem. 2016, 128, 3670-3674.

(9) (a) Cakmak, Y.; Kolemen, S.; Duman, S.; Dede, Y.; Dolen, Y.; Kilic, B.; Kostereli, Z.; Yildirim, L. T.; Dogan, A. L.; Guc, D.; Akkaya, E. U. Angew. Chem., Int. Ed. 2011, 50, 11937-11941. (b) Kolemen, S.; Isik, M.; Kim, G. M.; Kim, D.; Geng, H.; Buyuktemiz, M.; Karatas, T.; Zhang, X.-F.; Dede, Y.; Yoon, J.; Akkaya, E. U. Angew. Chem., Int. Ed. 2015, 54, 5340-5344.

(10) (a) Lim, S. H.; Thivierge, C.; Nowak-Sliwinska, P.; Han, J. Y.; van den Bergh, H.; Wagnieres, G.; Burgess, K.; Lee, H. B. J. Med. Chem. 2010, 53, 2865-2874.

(11) Duman, S.; Cakmak, Y.; Kolemen, S.; Akkaya, E. U.; Dede, Y. J. J. Org. Chem. 2012, 77, 4516-4527.

(12) Topel, S. D.; Cin, G. T.; Akkaya, E. U. Chem. Commun. 2014, 50, 8896-8899.

(13) Tram, K.; Yan, H. B.; Jenkins, H. A.; Vassiliev, S.; Bruce, D. Dyes Pigm. 2009, 82, 392-395.

(14) Jiao, L.; Yu, C.; Li, J.; Wang, Z.; Wu, M.; Hao, E. J. Org. Chem. 2009, 74, 7525-7528. 